\title{
ORIENTAÇÃO FARMACÊUTICA A PRATICANTES DE ATIVIDADE FÍSICA DE ENDURANCE: UM ESTUDO DE CASO
}

\author{
Pharmaceutical advice for endurance athletes: a case report
}

\author{
Naraiana Agapito ${ }^{{ }^{*}}$, Natalie Martins d'Avila ${ }^{1}$ e Marcos Antônio Segatto Silva ${ }^{2}$ \\ ${ }^{1}$ Curso de Farmácia \& Bioquímica da Universidade Federal de Santa Catarina (UFSC). \\ ${ }^{2}$ Professor Associado do Departamento de Ciências Farmacêuticas da \\ Universidade Federal de Santa Catarina (UFSC). \\ Campus Universitário - UFSC, 88040-970. Florianópolis - SC, Brasil.
}

*Autor para correspondência e-mail: naraagapito@yahoo.com.br

Recebido em 10/10/2007 - Aceito em 24/11/2008

\begin{abstract}
RESUMO: O uso dos chamados agentes ergogênicos no esporte de alto rendimento desencadeou um processo que representa atualmente uma das grandes preocupações na área das Ciências do Esporte. A equipe multiprofissional envolvida no preparo do atleta tem como função garantir a integridade de sua saúde, possibilitando a melhora em seu desempenho. Portanto, deve-se atentar para as necessidades nutricionais do indivíduo, que sofre intenso desgaste metabólico rotineiramente. No Brasil, tem sido observado um uso abusivo de suplementos alimentares em ambientes de práticas de exercícios físicos. Este trabalho visou demonstrar a importância da orientação farmacêutica a praticantes de atividade física de endurance através de um estudo de caso. Para tal, o sujeito do estudo, participante voluntário, foi selecionado com base nos critérios: ser esportista em fase de treinamento intenso, sob acompanhamento clínico. As informações foram obtidas mediante aplicação de questionário aberto e relatos com o objetivo de avaliar o perfil fisiológico do esportista e detectar a possível utilização de suplementos alimentares ou medicamentos por parte do mesmo. Através dos relatos, observou-se a dificuldade, por parte da equipe de treinamento e do indivíduo, em identificar as necessidades ideais de sais minerais durante a prática esportiva. Além disso, constatou-se o consumo freqüente de produtos vitamínicos e minerais. O grande apelo comercial gerado pelos produtos voltados a praticantes de atividades físicas favorece 0 uso abusivo ocasionando efeitos tóxicos e colaterais graves. Neste contexto, o profissional farmacêutico deve desempenhar suas atividades com embasamento científico visando uma orientação adequada quanto ao uso de suplementos alimentares e medicamentos para esportistas.
\end{abstract}

PALAVRAS-CHAVE: Atenção farmacêutica, exercício físico, suplementos alimentares.

ABSTRACT: The consumption of nutritional ergogenics within high performance sports is one of the major concerns in Sport Science nowadays. A multi-professional team involved in the preparation of an athlete has the responsibility of guaranteeing his/her health integrity as well as enhancing his/her performance. Therefore, it is important to monitor the nutritional needs of the athlete who suffers a significant metabolic waste during training routine. In Brazil, an abusive consumption of dietary supplements was observed in physical activity environments. This work aims to demonstrate the importance of pharmaceutical advice for endurance athletes through a case report. The individual of this case study was a volunteer and the selection was based on the following criteria: the individual should be a sportsman enrolled in an intense training program, being monitored by health professionals. Information was obtained from the sportsman through questionnaires and reports aiming the evaluation of his physiological profile and detection of possible consumption of dietary supplements or medicines. Through the individual's reports, it was observed that the health professionals supporting his training had difficulties in identifying the ideal necessities of mineral salts replacement during the physical activities. Therefore, it was detected a large consumption of vitamins and minerals through supplements. The significant marketing activity towards individuals who par-take physical activities leads to an abusive consumption of nutritional supplements causing toxicity and severe side effects. In this context, the pharmacist has to perform his role and advice sportsmen on dietary supplements as well as medicine consumption based on scientific evidence. 
Agapito, N. et al./Revista Eletrônica de Farmácia Vol 5(3), 09 - 22, 2008.

KEYWORDS: Pharmaceutical care, exercise, dietary supplements.

\section{INTRODUÇÃO}

O uso dos chamados agentes ergogênicos no esporte de alto rendimento desencadeou um processo que representa atualmente uma das grandes preocupações na área das Ciências do Esporte, tanto no combate ao doping, quanto no âmbito do uso indiscriminado de substâncias ativas e suplementos nutricionais com objetivos puramente estéticos. Estes agentes ergogênicos nutricionais caracterizam-se pela aplicação de estratégias e pelo consumo de nutrientes com grau de eficiência extremamente variável. Geralmente, os consumidores utilizam estas substâncias em doses muito acima do recomendável, o que também se constitui em uma preocupação, apesar de existirem grandes controvérsias quanto aos eventuais problemas causados à saúde em decorrência do uso indiscriminado das mesmas (NETO, 2001).

Com a finalidade ergogênica e estética, no Brasil, tem sido observado um uso abusivo de suplementos alimentares e substâncias ativas, sendo que, tal atitude tem aumentado em ambientes de práticas de exercícios físicos. Trata-se muitas vezes de um comércio ilegal, sem controle e que não sofre por parte dos órgãos governamentais controladores de muitos países uma avaliação de segurança e eficácia em sua produção. Esta prática, mesmo quando conta com a indicação de profissionais da medicina e da nutrição, muitas vezes é adotada sem uma base sólida de conhecimentos, portanto, de forma empírica (CARVALHO, 2003).

Um estudo patrocinado pelo Comitê Olímpico Internacional mostrou que alguns destes produtos podem apresentar, além dos componentes descritos nos rótulos, outras substâncias como os precursores de hormônios e testosterona, podendo ocasionar controles de doping positivos. Por esta razão, os atletas devem utilizar apenas produtos tradicionais, preferencialmente testados com antecedência, para assim impedirem o risco de um doping involuntário, pois mesmo que este não seja intencional, não evitará as prováveis punições. Como não é possível assegurar a qualidade deste tipo de produtos, e considerando que sua utilização como fator de aumento do desempenho físico não está demonstrada na literatura, o atleta deve exercer grande prudência na sua utilização (ROSE et al., 2004). No entanto, os atletas são responsáveis por conhecer as normas de seu Comitê Olímpico, Confederação Brasileira e Federação Internacional, além de informar ao seu médico pessoal ou farmacêutico de que é um atleta e está sujeito a controle de doping.

De acordo com o Código de Ética da Profissão Farmacêutica (Resolução no 417, de 29 de setembro de 2004), "o farmacêutico é um profissional da saúde, cumprindo-lhe executar todas as atividades inerentes ao âmbito profissional farmacêutico de modo a contribuir para a salvaguarda da saúde pública e, ainda, todas as ações de educação dirigidas à comunidade na promoção da saúde. O farmacêutico deverá adotar postura científica perante as práticas terapêuticas alternativas de modo que o usuário fique bem informado e possa melhor decidir sobre a sua saúde e bem-estar".

Portanto, a orientação do profissional farmacêutico em ambientes de práticas esportivas se faz necessária, pois o mesmo poderá informar o atleta quanto aos efeitos farmacológicos, efeitos toxicológicos, efeitos adversos, interações, posologia e contra-indicações relativas às substâncias ergogênicas. E ainda, orientar quanto ao controle do doping, no caso do atleta fazer uso de algum tipo de medicamento. O farmacêutico, ao trabalhar juntamente com os outros profissionais da saúde que compõem a equipe de preparo do atleta ou esportista, poderá contribuir para um melhor desempenho do mesmo, sem que este tenha sua saúde prejudicada.

O objetivo deste trabalho é demonstrar a importância da orientação farmacêutica em relação a esportistas e atletas praticantes de atividade física de endurance. De modo geral, espera-se uma conscientização por parte dos envolvidos na prática esportiva quanto estes riscos de administrarem-se substâncias sem orientação profissional.

\section{Praticantes de atividade física de endurance}

O atleta profissional é aquele que participa de um time organizado ou esporte individual que requer treino sistemático, competições regulares contra outros e disputa prêmios pela excelência de seu desempenho (MARON \& MITCHELL, 1994).

O interesse e a participação em competições desportivas aumentaram significativamente nos últimos anos e, sem dúvida nenhuma, as provas de ultra-resistência ou de longa duração são as que despertam maior fascínio (FERREIRA et al., 2001). Podemos entender por endurance a capacidade do atleta em exercer atividade física de longa duração (resistência), tais como natação, maratona, ciclismo e triatlon.

O triatlon, nas suas diferentes dimensões, constitui-se inigualável modelo de prova de alta intensidade e longa duração, notadamente o Ironman. Competições desta modalidade têm ganhado enorme repercussão nos veículos de comunicação e se tornado cada vez mais competitivas, com a profissionalização do esporte (BASSIT \& MALVERDI, 1998).

Atletas têm suas necessidades de energia e nutrientes baseadas no peso, altura, idade, sexo, taxa metabólica, composição corporal e principalmente, no tipo, freqüência, intensidade e duração do treinamento necessário para seu esporte (STEEN \& BUTTERFIELD, 2000; MONTERO et al., 2002, citados por CARVALHO, 2003a). 
Agapito, N. et al./Revista Eletrônica de Farmácia Vol 5(3), 09 - 22, 2008.

O treino regular e intenso de exercícios podem aumentar as necessidades de micronutrientes, devido ao aumento das taxas de degradação ou aumento das perdas corpóreas (MAUGHAN, 1999, citado por CARVALHO, 2003a). Freqüentemente os atletas treinam intensamente com descanso inadequado e ingerem poucas calorias, 0 que em combinação poderia comprometer seu sistema imune e expô-los a infecções e lesões (VENKATRAMAN et al., 2000, citados por CARVALHO, 2003a).

Existem situações nas quais há falhas nos esquemas de alimentação e reposição hidroeletrolítica, prejudicando o desempenho desportivo e colocando em risco a saúde dos praticantes de exercícios físicos, o que freqüentemente se observa em provas de longa duração (CARVALHO, 2003).

Devido ao desenvolvimento de aumento do processo metabólico através do exercício intensivo, estes indivíduos podem estar submetidos a situações prejudiciais a saúde. Torna-se necessário o acompanhamento de rotina por profissionais habilitados para identificar os possíveis riscos de saúde, fisiológicos e psicológicos, ao qual submete-se o indivíduo, e assim definir o estado clínico do mesmo. Devem ser realizados exames médicos específicos periodicamente para monitorização do estado de saúde do paciente, além de buscar histórico para detecção de possíveis tendências genéticas a complicações de saúde. Baseando-se em todas as informações, avalia-se a necessidade de uso de suplementação nutricional.

\section{O uso de suplementos alimentares por atletas}

Suplemento alimentar é todo alimento ou substância que fornece nutrientes além das necessidades normais. Estes são utilizados com objetivo de atingir as necessidades nutricionais aumentadas em algumas situações clínicas, prevenir ou corrigir estados de desnutrição ou deficiências de micronutrientes. Podem ser usados também como complemento alimentar, que é o alimento fornecido para completar o aporte de nutrientes resultante de uma alimentação insuficiente (SOCIEDADE BRASILEIRA DE NUTRIÇÃO, 2008).

A nutrição corresponde aos processos gerais de ingestão e conversão de substâncias alimentícias em nutrientes que podem ser utilizados para manter a função orgânica. Esses processos resultam em nutrientes capazes de gerar energia e são utilizados como substrato sintético, pois exercem diversas funções reguladoras no metabolismo celular. A dieta adequada é aquela capaz de repor os metabólitos consumidos para a geração de energia, assim como, garantir aporte suficiente de substratos para os processos de síntese envolvidos na manutenção da estrutura corporal. No entanto, a dieta ideal é aquela capaz de fornecer substratos para o desenvolvimento pleno do potencial do indivíduo, garantindo-lhe melhor desempenho físico e mental (BASSIT \& MALVERDI, 1998).

A Medicina Esportiva estabelece um conceito para o termo "agente ergogênico" que abrange todo e qualquer mecanismo, efeito fisiológico, nutricional ou farmacológico que seja capaz de melhorar a performance nas atividades físicas esportivas, ou mesmo ocupacionais (CARVALHO, 2003).

Buscando uma melhor performance, atletas e a população em geral recorrem ao uso de recursos ergogênicos. São tratamentos ou substâncias elaborados para aumentar o desempenho desportivo ou aprimorar a capacidade de realizar um trabalho físico. Há muito se sabe da utilização de várias substâncias ativas e agentes farmacológicos para fins de melhoria do desempenho. Entretanto, o uso de muitos desses agentes farmacológicos é considerado como doping, proibido pelo Comitê Olímpico Internacional (COI) e outras organizações atléticas, citando-se como exemplo o uso de hormônio do crescimento humano, esteróides anabolizantes, anfetaminas e eritropoetina. Devido a essa proibição, os indivíduos buscam, então, recursos ergogênicos que sejam eficientes e legais, e como os nutrientes são considerados legais, nos últimos anos, houve aumento significativo do consumo de suplementos nutricionais (FONTANA \& VALDES, 2003). Tal fato estimula um consumo desordenado de produtos polivitamínicos e poliminerais, os quais são comercializados muitas vezes desrespeitando a legislação vigente e consumidos sem orientação adequada.

Considerando a falta de informações sobre o consumo de produtos vitamínicos no País, Santos \& Filho (2002) realizaram um estudo com uma amostra de 894 estudantes ingressantes de uma universidade privada do Município de São Paulo. Verificou-se que 30,4\% usaram produtos vitamínicos nos três meses precedentes ao levantamento $(23,1 \%$ regularmente e $6,0 \%$ esporadicamente). Vitamina C e polivitamínicos foram os mais consumidos. Houve relação entre consumo regular de produtos vitamínicos e freqüência de atividade física. Apenas $21 \%$ dos consumidores informaram ter usado produtos vitamínicos por indicação profissional de médico, nutricionista ou treinador físico.

Porém, o consumo adequado de vitaminas e minerais é importante para a manutenção das diversas funções metabólicas do organismo. Assim, a ingestão inadequada desses micronutrientes pode potencialmente levar a estados de carência nutricional, sendo conhecidas diversas manifestações patológicas por ela produzidas (MELÉNDEZ, 1997).

Por outro lado, a equipe de treinamento também deve estar atenta, para evitar o doping involuntário, e orientar o atleta de maneira adequada. Toda medicação deve ter sua composição avaliada, pois parte de substâncias proibidas no esporte podem ser prescritas em doses terapêuticas vendidas livremente no Brasil. Segundo o Comitê Olímpico Brasileiro (2004), os diuréticos e betabloqueadores, por exemplo, são considerados medicamentos de uso proibido. Outro fator de perigo são os produtos ditos naturais e complementos vitamínicos que nas suas composições podem conter componentes proibidos. 
Agapito, N. et al./Revista Eletrônica de Farmácia Vol 5(3), 09 - 22, 2008.

\section{Orientação Farmacêutica}

A atenção farmacêutica foi definida pela primeira vez por Hepler \& Strand (1990) como a provisão responsável do tratamento farmacológico com o propósito de alcançar resultados concretos que melhorem a qualidade de vida dos pacientes. Posteriormente, a Organização Mundial da Saúde (OMS) estendeu o beneficio da Atenção Farmacêutica para toda a comunidade e ainda reconheceu o farmacêutico como um dispensador de atenção à saúde, que pode participar ativamente na prevenção de enfermidades e na promoção da saúde, junto com outros membros da equipe de saúde (IVAMA et al., 2002).

Segundo a proposta feita pelo Consenso Brasileiro de Atenção Farmacêutica (2002): A atenção farmacêutica é um modelo de prática farmacêutica, desenvolvido no contexto da Assistência Farmacêutica. Compreende atitudes, valores éticos, comportamentos, habilidades, compromissos e co-responsabilidades na prevenção de doenças, promoção e recuperação da saúde, de forma integrada à equipe de saúde. É a interação direta do farmacêutico com o usuário, visando uma farmacoterapia racional e a obtenção de resultados definidos e mensuráveis, voltados para a melhoria da qualidade de vida. Esta interação também deve envolver as concepções dos seus sujeitos, respeitadas as suas especificidades bio-psico-sociais, sob a ótica da integralidade das ações de saúde (IVAMA et al., 2002).

O farmacêutico informa e orienta o paciente sobre o uso adequado dos medicamentos. São elementos importantes da orientação, entre outros, a ênfase no cumprimento da dosagem, a influência dos alimentos, a interação com outros medicamentos, o reconhecimento de reações adversas potenciais. $O$ acesso à Atenção Farmacêutica é um direito do usuário assegurado pela legislação sanitária e pelo código de defesa do consumidor (CLAUMANN, 2003).

$\mathrm{Na}$ Tabela 1, a seguir, observam-se alguns aspectos e qualidades que devem ser desenvolvidos em busca da construção de um perfil profissional mais adequado às exigências do mercado no novo contexto da saúde.

Tabela 1. Perfil do Profissional Farmacêutico.

\begin{tabular}{|c|c|}
\hline ASPECTOS & QUALIDADES \\
\hline \multirow[t]{2}{*}{ Comunicação } & - estar sempre informado \\
\hline & - ser especialista em prestar informações \\
\hline \multirow{2}{*}{$\begin{array}{l}\text { Prestação de } \\
\text { serviços }\end{array}$} & • conhecer as aspirações da população \\
\hline & - compromisso com a qualidade total (produtos e serviços) \\
\hline \multirow[t]{2}{*}{ Político/econômico } & - especialista em redução de custos \\
\hline & - ser flexível \\
\hline \multirow[t]{2}{*}{ Social } & - ser comunicativo (educador por excelência) \\
\hline & - ético \\
\hline \multirow[t]{2}{*}{ Organização } & - ter planejamento (metas escritas e estratégias para alcançá-las) \\
\hline & - proceder ao registro das ações \\
\hline \multirow[t]{3}{*}{ Técnico } & - ser competente \\
\hline & - estar integrado na equipe \\
\hline & - participar das instâncias colegiadas \\
\hline \multirow[t]{2}{*}{ Pessoal } & • inspirar confiança \\
\hline & $\begin{array}{l}\text { - destacar-se como profissional (capacitar-se para dar } \\
\text { resolubilidade) }\end{array}$ \\
\hline
\end{tabular}

Fonte: Tuma (2000).

Em Atenção Farmacêutica, a relação direta entre um farmacêutico e um paciente é um contrato profissional onde a segurança e o bem estar do paciente são confiados ao farmacêutico, que se compromete, através de ações profissionais competentes, a servir ao melhor interesse do paciente (CLAUMANN, 2003). 
Agapito, N. et al./Revista Eletrônica de Farmácia Vol 5(3), 09 - 22, 2008.

\section{MATERIAL E MÉTODOS}

Este trabalho foi realizado por meio de um estudo de caso, sendo que o mesmo foi submetido ao Comitê de Ética em Pesquisa (CEP) da Universidade Federal de Santa Catarina (UFSC), protocolo número157/05.

O estudo de caso, assim como o método qualitativo, é utilizado quando o fenômeno a ser estudado é amplo e complexo, onde o corpo de conhecimentos existente é insuficiente para suportar a proposição de questões causais e nos casos em que o fenômeno não pode ser estudado fora do contexto onde naturalmente ocorre (BONOMA, 1985; citado por BRESSAN, 2000).

A seleção do sujeito do estudo foi realizada de maneira aleatória. O critério para inclusão foi um histórico de treinamento de pelo menos 06 (seis) meses de atividade física do tipo endurance com freqüência diária, na qual teve uma alimentação balanceada e monitorada por um profissional qualificado, o nutricionista. As informações foram obtidas mediante relatos feitos pelo próprio esportista e aplicação de questionário aberto com o objetivo de detectar a utilização de suplementos nutricionais ou medicamentos, averiguando possíveis níveis de evidências de pesquisas cientificas relacionadas aos mesmos.

Portanto, o participante voluntário escolhido para o estudo de caso foi um esportista em fase de treinamento para o Ironman (3,8 km de natação, $180 \mathrm{~km}$ de ciclismo e $42 \mathrm{~km}$ de corrida). O esportista completou uma rotina de treinamento de 26 semanas, praticando aproximadamente cinco horas de atividade física por dia. Perfazia três semanas de treino com alto esforço físico seguida de uma semana de recuperação, onde o treinamento é menos intenso.

\section{RESULTADOS E DISCUSSÃo}

O estudo de caso retratou a situação típica de atletas praticantes de atividades físicas de endurance. $\mathrm{Na}$ tabela 2, são apresentadas informações pessoais e atividades físicas praticadas pelo esportista.

Tabela 2. Informações pessoais e atividades físicas praticadas pelo esportista.

\begin{tabular}{l|l}
\hline \multicolumn{2}{c}{ INFORMAÇÕES PESSOAIS } \\
\hline Sexo & Masculino \\
Idade & 36 anos \\
Profissão & Professor de educação física \\
Estado civil & casado \\
Altura & 1,70 m \\
Peso & 65 Kg \\
\hline \multirow{2}{c}{ ATIVIDADES FíSICAS PRATICADAS PELO PARTICIPANTE } \\
\hline Modalidade esportiva & Triatlon \\
Freqüência de treinamento & $12 \mathrm{~h} 30$ às 17h e 19h30 às 20h30, diariamente \\
Atividades físicas & $\begin{array}{l}\text { Musculação (três vezes por semana) } \\
\text { Yoga (duas vezes por semana) } \\
\text { Surfe (três vezes por semana) } \\
\text { Corrida (três vezes por semana) } \\
\text { Ciclismo (três vezes por semana) } \\
\text { Natação (três vezes por semana) }\end{array}$ \\
\hline
\end{tabular}

Em relação às informações clínicas, o sujeito possui alimentação supervisionada e, devido ao grande desgaste físico, recebe os seguintes suplementos nutricionais por parte da equipe profissional que o acompanha:

- WHEY PROTEIN ${ }^{\circledR}$ (proteína do soro do leite) - após os treinos.

- $\mathrm{BCAA}^{\circledR}$ (valina, leucina, isoleucina e vitamina B6) - $4 \mathrm{~g}$ por dia, antes e durante os treinos.

- SUPRADYN ${ }^{\circledR}$ (polivitamínico e polimineral) - 1 comprimido por dia, longe das principais refeições.

- Vitamina C - 500mg por dia.

- Vitamina E - 400 mg por dia, à noite ou após os treinos. 
Agapito, N. et al./Revista Eletrônica de Farmácia Vol 5(3), 09 - 22, 2008.

Durante a competição do Ironman, realizada na cidade de Florianópolis em Santa Catarina, foi relatado pelo esportista o uso do MOVATEC ${ }^{\circledR}$ (Meloxicam de $150 \mathrm{mg}$ ). E como histórico familiar de doenças, a avó materna apresenta angina e a mãe apresenta hipertensão.

Como relatos, observou-se a dificuldade, por parte da equipe de treinamento e do indivíduo, em identificar as necessidades ideais de sais minerais durante a prática esportiva. Além disso, constatou-se o consumo freqüente de produtos vitamínicos e minerais.

Após o período de treinamento de 26 semanas, o indivíduo apresentou aproximadamente $10 \%$ de perda de peso e sintomas gastrintestinais, como princípio de diarréia e cólicas abdominais. Na véspera da prova de Ironman, o esportista apresentou hematúria macroscópica. A hipótese apresentada pela equipe médica do esportista foi de uma possível isquemia gastrintestinal.

Sabe-se que os atletas, particularmente os de resistência, forçam rotineiramente seus corpos a ponto de alterar seus níveis de líquido e eletrólito. Em alguns casos, estas alterações podem comprometer o desempenho e a saúde do atleta, porém a resposta fisiológica do corpo a tais alterações é complexa e ainda não compreendida completamente (HOSEY \& GLAZER, 2004). No entanto, em diversos estudos foi observado que atividades físicas de endurance podem provocar sintomas gastrintestinais como vômito, náusea, azia, diarréia, cólicas abdominais, perda de apetite, sangramento e aceleração dos movimentos intestinais (SULLIVAN, 1981; CANTWELL, 1981; SIMREN, 2002; VAN NIEUWENHOVEN et al., 2004, citados por LIRA \& VANCINI, 2005).

Durante o exercício físico intenso, a diminuição do fluxo sanguíneo intestinal pode chegar a $80 \%$, comprometendo a região (GRANGER et al., 1980; BERG et al., 1999, citados por LIRA \& VANCINI, 2005). Essa redução é decorrente da vasoconstrição do leito vascular esplâncnico pela ação de catecolaminas sobre os receptores alfa-adrenérgicos via sistema nervoso simpático (GRANGER et al.,1980; citado por LIRA \& VANCINI, 2005). Esta estimulação aumenta o fluxo sanguíneo nos músculos ativos e na pele (para termorregulação), enquanto mantém o fluxo sanguíneo para o cérebro e coração (CLAUSEN, 1977; citado por LIRA \& VANCINI, 2005). O comprometimento da mucosa pela redução drástica do fluxo sanguíneo aumenta a permeabilidade intestinal, pois as junções comunicantes tornam-se relaxadas. A passagem de compostos agressivos através dessas junções pode estimular a migração de neutrófilos (PALS et al.,1997; LAMBERT et al., 2001; citados por LIRA \& VANCINI, 2005), que quando ativados podem disparar uma resposta imune local com geração de radicais livres e liberação de enzimas lisossomais, danificando ainda mais o epitélio intestinal (BASKA et al., 1990; PALS et al., 1997; citados por LIRA \& VANCINI, 2005). Essa seqüência de eventos pode contribuir para potencializar o aumento da permeabilidade intestinal e a resposta inflamatória, ocasionando o desenvolvimento de sintomas gastrintestinais (PALS et al., 1997; LAMBERT et al., 2001; citados por LIRA \& VANCINI, 2005).

Outra via que pode levar ao aumento da permeabilidade intestinal é a redução do fluxo mesentérico, acarretando geração de espécies reativas de oxigênio (ROS). A isquemia mesentérica contribui para o acúmulo de hipoxantina e conversão da enzima xantina desidrogenase a xantina oxidase. Esta conversão é mediada pelo aumento intracelular do cálcio que ativa a calpaína, enzima responsável por essa conversão. Quando o fluxo sanguíneo é restaurado, a xantina oxidase catalisa a produção de ROS a partir do oxigênio molecular e da hipoxantina. O resultado é uma resposta inflamatória que pode colaborar para o desenvolvimento de sintomas gastrintestinais durante o exercício (BARON et al., 1994; citado por LIRA \& VANCINI, 2005). A diminuição do fluxo sanguíneo intestinal pode prejudicar a permeabilidade e a absorção de nutrientes, aumentando os níveis dessas substâncias na luz e produzindo diarréia. A isquemia do trato gastrintestinal diminui a oferta de oxigênio e de metabólitos (SATO et al., 1979; GORES et al., 1989; citados por LIRA \& VANCINI, 2005). Além da estimulação simpática, outro possível mecanismo envolvido na redução do fluxo mesentérico é a ativação, dependente da intensidade do exercício, do sistema renina-angiotensina durante a hipovolemia associada ao exercício que é decorrente da desidratação (BUKLEY et al., 1985; WILCOX et al.,1995; citados por LIRA \& VANCINI, 2005).

Níveis críticos de isquemia podem ser alcançados quando o exercicio é feito em condições extremas, tais como hipertermia, desidratação, hipoglicemia, hipoxia ou pela combinação destes fatores (BROUNS \& BECKERS, 1993; GISOLFI, 2000; citados por LIRA \& VANCINI, 2005). O estudo realizado por Lira \& Vancini (2005) para reduzir a ocorrência de sintomas gastrintestinais em atletas, recomenda: planejamento do regime de hidratação durante as sessões de treinamento; evitar o consumo de soluções hipertônicas de carboidratos (não mais que 500 mOsm); procurar não consumir cafeína, altas doses de vitamina $\mathrm{C}$ e bicarbonato e evitar o uso de fármacos que atuem sobre o sistema gastrintestinal.

A hematúria comumente ocorre em atletas corredores de longas distâncias (>10 km) e normalmente demonstra-se assintomática. Na maioria das vezes, pronuncia-se no primeiro ato de urinar após a prática de atividade física, normalizando após $72 \mathrm{~h}$ e demonstra ser independente da intensidade da atividade física. A prevalência de relação entre hematúria e prática de atividade física de corrida é de 20 a $25 \%$ para corredores de distâncias de 21 a $90 \mathrm{~km}$. Coloração vermelha ou rósea da urina depois de uma corrida pode não apenas ser hematúria, mas também mioglobinúria ou hemoglobinúria (UBELS et al., 1999).

\section{Equilíbrio Hidroeletrolítico}

O esporte de alto rendimento impõe a necessidade de um estudo minucioso sobre a influência do exercício nas respostas fisiológicas. Neste contexto, tem-se conhecimento de que o exercício de longa duração pode 
Agapito, N. et al./Revista Eletrônica de Farmácia Vol 5(3), 09 - 22, 2008.

provocar um quadro de desidratação, produzindo ainda alterações no equilíbrio eletrolítico (MARINS et al., 2003). Sabe-se que a reposição hídrica adequada durante atividades físicas é importante para reposição de perdas pelo suor. Deste modo, mantém-se o desempenho durante a atividade evitando desidratação e garantido a termorregulação corporal (BARR et al., 1991). O sódio está diretamente envolvido na manutenção do potencial de membrana de repouso e na geração do potencial de ação dos nervos e dos músculos. Além disso, o sódio é o principal eletrólito que determina o volume do líquido extracelular. Se o estoque de sódio diminui, o volume do líquido extracelular, incluindo o plasma, é reduzido. Isso pode causar problemas importantes relacionados à manutenção da pressão arterial média e da temperatura corporal (POWERS \& HOWLEY, 2000).

Apesar das tentativas de repor água durante as corridas de maratona, alguns corredores perdem $8 \%$ de seu peso corporal. Tendo-se em vista que a perda de água superior a $3 \%$ é considerada potencialmente prejudicial, existe uma evidente necessidade de manter o balanço hídrico (POWERS \& HOWLEY, 2000). A desidratação é comum durante eventos de longa duração, onde os corredores evitam ingerir fluido devido à dificuldade de beber enquanto correm e pelo desconforto estomacal. A desidratação reduz o volume sanguíneo, agravando a redução do fluxo sanguíneo intestinal durante o exercício (LIRA \& VANCINI, 2005). Rehrer e colaboradores (1990), citados por Lira \& Vancini (2005), verificaram que a perda de 3,5 a 4,0\% do peso corporal durante o exercício está associada ao aumento da incidência de sintomas gastrintestinais.

A desidratação também ocorre em indivíduos que ingerem grande volume de fluidos, porém não repõem os sais adequadamente (LIRA \& VANCINI, 2005). A água pode ser uma boa opção de reidratação para o exercício. Entretanto, para as atividades prolongadas, de mais de uma hora de duração, ou para as atividades de elevada intensidade, apresenta as desvantagens de não conter sódio e carboidratos e de ser insípida, favorecendo a desidratação voluntária e dificultando o processo de equilíbrio hidroeletrolítico (CARVALHO, 2003).

Existem evidências de que a hiponatremia venha a representar uma das complicações mais graves durante exercícios prolongados (SPEEDY et al., 1999). A concentração plasmática de sódio considerada normal encontrase entre 136 e $142 \mathrm{mmol} / \mathrm{l}$. Quando ocorre desequílibrio hidroeletrolítico resultando na queda anormal, abaixo de $135 \mathrm{mmol} / \mathrm{l}$, desta concentração de sódio tem-se a hiponatremia (MURRAY et al., 2003).

Quanto as teorias de possíveis causas de hiponatremia, existem duas que relacionam a mesma com a atividade física. A primeira teoria sugere falha na restituição de sódio, o qual é eliminado através do suor, causando assim desidratação. Já a segunda propõe que a hiponatremia desenvolve-se através de ingestão exagerada de líquidos, gerando sobrecarga de fluidos (TWERENBOLD et al., 2003).

Foi realizado um estudo com o objetivo de averiguar as necessidades de sódio durante atividade física. Para tal, utilizaram-se atletas femininas devido ao fato de hiponatremia ser mais comum em mulheres. Estas consumiram 1 litro de líquido por hora, o que representa o máximo geralmente recomendado. Os resultados demonstrando ganho de peso sugeriram que o excesso de fluido é a causa da hiponatremia em $69 \%$ desta população em estudo. As razões para a falha na excreção do excesso de fluido são: anormalidades das funções renais, elevados níveis de hormônios antidiuréticos, limitações na absorção intestinal, retenção líquida no trato gastrointestinal, ou combinação desses fatores. Sugere-se que 1 litro de fluido por hora durante uma corrida com quatro horas de duração é suficiente para causar retenção hídrica em mulheres durante atividade física prolongada. No caso de excesso de fluidos, a reposição de sódio é imprescindível. Recomenda-se então reposição de $680 \mathrm{mg} / \mathrm{h}$ para mulheres a fim de minimizar os riscos de hiponatremia (TWERENBOLD et al., 2003).

De 371 atletas (62\% de todos os finalistas) pesados após prova de Ironman Triathlon na África do Sul, aquele que havia ganhado mais peso (aproximadamente $3,6 \mathrm{~kg}$ ) durante o percurso foi o único competidor a desenvolver hiponatremia sintomática. Após recuperação, excretou um excesso de 4,6 litros de urina. Este relato confirma que hiponatremia sintomática é causada por administração em excesso de fluidos, independente de perdas apreciáveis de $\mathrm{NaCl}$. Conseqüentemente, os atletas devem ser orientados a não ingerir grande volume de líquidos exageradamente (NOAKES et al., 2004).

De acordo com Raia (2008) corredores necessitam de 400 a $800 \mathrm{mg}$ de sódio por hora quando submetidos a competições em condições altas de temperatura. Grande parte das bebidas isotônicas não possui em sua composição sódio suficiente para suprir as necessidades dos atletas. Se a concentração de sódio estiver abaixo do necessário, o organismo poderá liberar água para evitar um estado de hiponatremia. Assim, é possível desenvolver um estado de desidratação mesmo que o indivíduo esteja urinando normalmente.

A concentração de sódio no suor varia individualmente, de acordo com vários fatores, como a idade, o grau de condicionamento e a aclimatização ao calor. A diminuição da osmolaridade plasmática produz um gradiente osmótico entre o sangue e o cérebro, causando apatia, náusea, vômito, consciência alterada e convulsões, que são algumas das manifestações neurológicas da hiponatremia. A inclusão de sódio nas bebidas reidratantes promove maior absorção de água e carboidratos pelo intestino durante e após o exercício. Isto se dá porque o transporte de glicose na mucosa do enterócito é acoplado com o transporte de sódio, resultando numa maior absorção de água (CARVALHO, 2003). Em exercícios prolongados, que ultrapassam uma hora de duração, recomenda-se beber líquidos contendo de 0,5 a $0,7 \mathrm{~g} / \mathrm{l}$ de sódio, que corresponde a uma concentração similar ou mesmo inferior àquela do suor de um indivíduo adulto (CARVALHO, 2003). Segundo Carvalho (2003) o sódio possui recomendação de grau $A$, que representa sempre usar, pois possui eficácia e segurança comprovada, e nível de evidência 2, que significa evidência baseada em poucos estudos randomizados e controlados, porém concordantes. 
Agapito, N. et al./Revista Eletrônica de Farmácia Vol 5(3), 09 - 22, 2008.

Os sinais de deficiência prolongada e severa de sódio são as cãibras musculares e redução do apetite. $O$ melhor teste simples para a avaliação do sucesso dos métodos de reposição de sal/água é pesar o atleta diariamente (POWERS \& HOWLEY, 2000). Para alcançar a quantidade de sódio necessária, o atleta poderá fazer uso de suplementos. THERMOTABS ${ }^{\circledR}$ é uma das suplementações de sódio existentes no mercado. A quantidade de sódio por tablete é de $179 \mathrm{mg}$. Observou-se a dificuldade, por parte da equipe de treinamento e do indivíduo, em identificar as necessidades ideais de sais minerais durante a prática esportiva. Portanto, a seguir serão discutidos o uso de minerais e vitaminas por parte dos atletas.

\section{Polivitamínicos e Poliminerais}

Além dos macronutrientes (carboidratos, lipídeos e proteínas) os seres humanos dependem da ingestão de pequenas quantidades de vitaminas e íons inorgâncios, conjuntamente denominados micronutrientes (MARZZOCO \& TORRES, 1999).

Em estudos realizados por Froiland e colaboradores (2004) a freqüência de uso de suplementos foi pesquisada, e realizaram-se comparações entre sexo e modalidade esportiva. Obteve-se que, $89 \%$ da população do estudo já usaram suplementos nutricionais. Muitos atletas não consideraram bebidas energéticas e produtos de reposição calórica como suplementos. Mulheres apresentaram preferência ao consumo de cálcio e polivitamínicos. Homens consumiam mais ginseng (Panax ginseng), aminoácidos, glutamina, whey protein e produtos para ganho de massa muscular. Os suplementos mais freqüentemente utilizados foram bebidas energéticas (73\%), produtos para reposição calórica (61.4\%), polivitamínicos $(47.3 \%)$, creatina (37.2\%), e vitamina C (32.4\%). O uso de suplementos variou significativamente de acordo com diferentes modalidades esportivas. Mulheres demonstraram preferência em obter informações referentes a suplementos através de membros familiares, e os homens através de nutricionistas, colegas atletas, amigos ou treinador. Atletas femininas demonstraram utilizar suplementos por questões de saúde ou para corrigir dietas inadequadas, enquanto homens relataram usar suplementos para aumentar agilidade, velocidade e força, ou para ganho de massa muscular.

Existem questionamentos sobre a eficácia dos micronutrientes combinados dentro de um suplemento devido as possíveis interações entre os nutrientes ou interferências em sua absorção. Tem-se levantado algumas preocupações em relação aos efeitos negativos das interações entre diferentes nutrientes em um suplemento de múltiplas vitaminas e minerais. Porém, é certo que alguns nutrientes competem para serem absorvidos, porém se ingeridos em quantidades suficientes os mesmos não terão sua absorção comprometida. Entretanto, há benefícios ao se combinar alguns nutrientes devido a melhora no transporte e ao aumento da absorção, como por exemplo, a vitamina $A$ que melhora $o$ transporte de ferro e a vitamina $C$ que aumenta a absorção do ferro. A maior preocupação em relações as interações ocorre com os minerais (HUFFMAN et al., 1998).

Pesquisadores avaliaram a peroxidação lipídica como principal indicação da indução de radicais livres pela atividade física. Notou-se que radicais livres também podem inativar complexos enzimáticos, danificar DNA e RNA, promover mutações celulares e câncer, podendo ainda estar associado a outras ações (KANTER, 1998). Também se deve observar que radicais livres são continuamente produzidos no organismo, e alguns possuem efeitos benéficos, notavelmente como parte do sistema imunológico natural humano. Não se sabe ao certo se os compostos antioxidantes ingeridos por período prolongado afetam esses aspectos positivos dos radicais livres.

Um estudo de Meydani e colaboradores. (1993), citado por Kanter (1998), sugere que pessoas idosas e fisicamente ativas podem ser beneficiadas com o uso de suplementação de substâncias antioxidantes. As vitaminas C, E e A e outros são capazes de restringir a propagação das reações em cadeia e as lesões induzidas pelos radicais livres. Quanto aos minerais, além do selênio, o zinco é freqüentemente mencionado na literatura como um mineral "antioxidante" envolvido nos mecanismos celulares de defesa contra os radicais livres (BIANCHI \& ANTUNES, 1999).

Conforme a Tabela 3, as recomendações diárias dos micronutrientes são: vitamina C, 50-200 mg; vitamina $\mathrm{E}, 10 \mathrm{mg}$; ferro, $10 \mathrm{mg}$; e zinco, $11 \mathrm{mg}$. O esportista faz uso de $650 \mathrm{mg}$ de vitamina C (150 mg do SUPRADYN ${ }^{\circledR} \mathrm{e}$ $500 \mathrm{mg}$ diárias); $410 \mathrm{mg}$ de vitamina $\mathrm{E}$ (10 mg do SUPRADYN ${ }^{\circledR}$ e $400 \mathrm{mg}$ diárias); $10 \mathrm{mg}$ de ferro (SUPRADYN ${ }^{\circledR}$ ) e $0,5 \mathrm{mg}$ de zinco $\left(\right.$ SUPRADYN $\left.^{\circledR}\right)$. Portanto, é importante ressaltar que as recomendações diárias de vitaminas e minerais referem-se a um adulto não praticante de atividades físicas. Deste modo, observa-se a necessidade de pesquisas científicas quanto a reposição destes micronutrientes a praticantes de atividade física de alta intensidade e longa duração, já que os mesmos possuem um gasto metabólico acentuado.

Tabela 3. Níveis de recomendações diárias de vitamina C, vitamina E, ferro e zinco.

\begin{tabular}{c|c}
\hline Suplementos alimentares & Recomendação diária \\
\hline Vitamina C & $50-200 \mathrm{mg}$ \\
Vitamina E & $10 \mathrm{mg}$ \\
Ferro & $10 \mathrm{mg}$ \\
Zinco & $11 \mathrm{mg}$ \\
\hline
\end{tabular}


Agapito, N. et al./Revista Eletrônica de Farmácia Vol 5(3), 09 - 22, 2008.

Fonte: Mello \& Mendes (2008); Carvalho (2003); Lukaski (1996).

\title{
Vitaminas
}

As vitaminas são co-fatores essenciais em reações enzimáticas envolvidas em produção de energia e metabolismo protéico, motivo pelo qual recebem atenção maior quando se trata da performance física de atletas (BROUNS, 1997). Em estudos realizados por Santos \& Filho (2002) entre universitários de São Paulo, já citado anteriormente, verificou-se que cerca de $30 \%$ da população estudada consumiu produtos vitamínicos no período estudado. Note-se que a maioria utilizou os produtos vitamínicos sem indicação profissional, ou seja, sem que houvesse sido detectada a necessidade de suplementação da dieta, caracterizando a prática de automedicação. Massad e colaboradores (1995) citados por Santos \& Filho (2002), por exemplo, verificaram que 41,7\% dos estudantes-atletas entrevistados consumiam polivitamínicos, e 29,7\% usavam suplementos de vitamina C, proporções bem superiores à população geral.

Para atletas em regime de treinamento intenso, tem sido sugerido, o que tem gerado controvérsia, o consumo de vitamina $C$ entre 500 e $1.500 \mathrm{mg} /$ dia (proporcionaria melhor resposta imunológica e antioxidante) e de vitamina $\mathrm{E}$ (aprimoraria a ação antioxidante). A documentação científica permite que os profissionais qualificados, nutricionistas e médicos prescrevam de forma sistemática vitamina C e E para atletas, com a ressalva de que esta atitude se baseia em um baixo grau de evidência científica. As vitaminas $\mathrm{C}$ e $\mathrm{E}$ possuem recomendação de grau $\mathrm{C}$ e nível de evidência 7, conforme a tabela 4. Para a determinação do grau de recomendação, além do nível de evidência científica, foram levados em consideração a aplicabilidade e o custo-benefício e o custo-efetividade da recomendação, dentre outros aspectos. As posições assumidas foram adotadas segundo os critérios sugeridos pela Comissão de Cardiologia Baseada em Evidência da Sociedade Brasileira de Cardiologia e Associação Médica Brasileira (CARVALHO, 2003).

Tabela 4. Classificação segundo o grau de recomendação e o nível de evidência científica.

\section{NÍVEL DE EVIDÊNCIA}

\begin{abstract}
Nível 1: evidência baseada em muitos estudos randomizados, controlados, amplos, concordantes e com poder estatístico adequado; preferencialmente com revisão sistemática conclusiva.

Nível 2: evidência baseada em muitos estudos randomizados, controlados, concordantes e de médio porte ou metanálises de vários estudos desta natureza, pequenos ou de médio porte.

Nível 3: evidência baseada em poucos estudos randomizados, controlados e de ótima qualidade.

Nível 4: evidência baseada em mais de um estudo coorte, de ótima qualidade.

Nível 5: evidência baseada em mais de um estudo caso-controle, de qualidade.

Nível 6: evidência baseada em mais de uma série de casos de alta qualidade. Inclui registros.

Nível 7: evidência baseada em apenas: extrapolações de resultados coletados para outros propósitos (testar outras hipóteses); conjecturas racionais, experimentos com animais, ou baseados em modelos mecanísticos de fisiopatologia e/ou mecanismos de ação; conduta antiga baseada em prática comum; opiniões sem referência a estudos anteriores.
\end{abstract}

\section{GRAU DE RECOMENDAÇÃO}

A = Sempre usar. Recomendação conclusiva, sendo adotada por uma unanimidade; conduta conclusivamente útil e segura; eficácia e segurança comprovadas. Quase sempre se requer níveis de evidência 1 ou 2 para que este grau de recomendação seja adotado.

B = Deve ser geralmente indicada. Recomendação considerada aceitável, mas com ressalvas; conduta aceitável e segura; grande potencial de utilidade, mas ainda sem comprovação conclusiva, com nível de evidência menos sólido.

C = Fica a critério pessoal usar. Recomendação indefinida; conduta a respeito da qual não há evidência segura a favor ou contra, quanto à eficácia e segurança.

D = Em geral não se deve usar. Conduta não recomendada, embora possa em algum contexto excepcional ser adotada, tratando-se de opção muito fraca; evidência mínima de eficácia e segurança, embora se vislumbre algum potencial de utilidade em algumas circunstâncias.

E = Nunca usar. Não recomendada por unanimidade.

Fonte: Carvalho (2003).

A vitamina $E$ constitui o antioxidante lipossolúvel mais efetivo encontrado na natureza, e importante fator de proteção contra a peroxidação lipídica nas membranas celulares e na circulação sangüínea. Devido às propriedades químicas das vitaminas $\mathrm{C}$ e $\mathrm{E}$ e dos carotenóides, substâncias altamente reativas e facilmente oxidadas podem agir como parte do sistema de defesa antioxidante do organismo humano, quando presentes em 
Agapito, N. et al./Revista Eletrônica de Farmácia Vol 5(3), 09 - 22, 2008.

quantidades fisiológicas e sob determinadas condições intracelulares, como, por exemplo, a pressões parciais fisiológicas de oxigênio. Ao contrário, em altas concentrações e à pressões parciais de oxigênio elevadas podem funcionar como agentes oxidantes, contribuindo para a formação de radicais livres. Assim, o termo "antioxidante" deve ser utilizado com cautela, sendo proposto o termo "moduladores fisiológicos", por ser mais abrangente e incluir, inclusive, os efeitos adversos eventualmente resultantes do uso abusivo dessas substâncias (SILVA \& NAVES, 2001).

Segundo a Portaria no 40, de 13 de janeiro de 1998, regulamento que estabelece normas para níveis de dosagens diárias de vitaminas e minerais em medicamentos, consideram-se os medicamentos como de "Venda Sem Exigência de Prescrição Médica" quando os níveis diários indicados para quaisquer dos componentes ativos situem-se até os limites considerados seguros. Já os medicamentos de "Venda Com Exigência de Prescrição Médica", são quando os níveis diários indicados dos componentes ativos situem-se acima dos limites considerados seguros por este regulamento, ou sempre que estiverem contidos em formulações para uso injetável. No entanto, de acordo com a Portaria no 32, de 13 de janeiro de 1998, os suplementos vitamínicos e/ou minerais devem conter um mínimo de $25 \%$ e no máximo até $100 \%$ da Ingestão Diária Recomendada (IDR) de vitaminas e ou minerais, na porção diária indicada pelo fabricante, não podendo substituir os alimentos, nem serem considerados como dieta exclusiva. E ainda, é proibida toda e qualquer expressão no rótulo que se refira ao uso do suplemento para prevenir, aliviar, tratar uma enfermidade ou alteração do estado fisiológico.

\section{Minerais}

Minerais são elementos inorgânicos amplamente distribuídos na natureza. São participantes ativos, ajudam no controle de muitos processos metabólicos do corpo. Eles possuem papéis vitais no metabolismo humano: como crescimento, ativação, regulação, transmissão e controle. Demorou-se muito para identificar as funções dos minerais, mas à medida que se progride na identificação dos ciclos vitais, valorizam-se mais estas funções. Podem ser classificados em minerais maiores (cálcio, fósforo, magnésio, sódio, potássio e cloro) e elementos traços (ferro, iodo, zinco, cobre, manganês, crômio, cobalto, selênio, molibdênio e flúor) quando as necessidades são superiores ou inferiores a $100 \mathrm{mg} / \mathrm{dia}$, respectivamente. (MELLO \& MENDES, 2008).

Mais especificamente, é importante a avaliação do estado nutricional relativo ao ferro, pela sua capacidade de transporte de oxigênio, interferindo, quando alterada, diretamente no desempenho do atleta e do zinco devido a sua participação no metabolismo intermediário do exercício, sua função imune e antioxidante (CARVALHO, 2003a). Lukaski e colaboradores (1996), estudando nadadores americanos de elite, observaram que a ingestão de zinco, cobre e ferro era inferior à necessidade diária, apesar de a ingestão energética estar adequada. Neste contexto, abaixo serão discutidas as principais funções e a importância do uso de dos minerais zinco e ferro na prática esportiva.

\section{1) Zinco}

O zinco participa de muitas reações do metabolismo celular, incluindo processos fisiológicos, tais como função imune, defesa antioxidante, crescimento e desenvolvimento (MAFRA \& COZZOLINO, 2004). A importância do mesmo na imunomodulação e na influência no curso e desenvolvimento de infecções é bastante evidenciado e reconhecido pela literatura (BHASKARAM, 2002).

Diversas enzimas e proteínas contendo zinco participam do metabolismo de proteínas, carboidratos, lipídeos e ácidos nucléicos. Encontra-se ainda envolvido na estabilização de membranas estruturais e na proteção celular, prevenindo a peroxidação lipídica. Seu papel fisiológico como antioxidante é evidenciado por 2 mecanismos: proteção de grupos sulfidrilas contra oxidação, como ocorre com a enzima ácido aminolevulínico desidratase e na inibição da produção de espécies reativas de oxigênio por metais de transição como ferro e cobre. $O$ zinco participa da estrutura da superóxido dismutase (SOD), sendo a atividade desta enzima reduzida pela deficiência deste mineral (MAFRA \& COZZOLINO, 2004).

Ao contrário do que ocorre com o ferro, o organismo excreta consideráveis quantidades de zinco via secreções intestinais como parte de seu mecanismo homeostático (CARVALHO, 2003a). A deficiência de zinco leva a redução na resistência à imunidade e cicatrização de feridas (SCHWENK \& COSTLEY, 2002). Sua deficiência em atletas pode gerar anorexia, perda de peso significativa, fadiga, queda no rendimento em provas de endurance e risco de osteoporose, razão pela qual tem sido sugerida a utilização em suplementação alimentar. Entretanto, as evidências científicas não justificam o uso sistemático do zinco em suplementação nutricional. $O$ zinco possui recomendação de grau E e nível de evidência 7 (CARVALHO, 2003).

É conhecido que o exercício pode mudar agudamente as concentrações de zinco circulante. Entretanto, a aparente diminuição das concentrações de zinco circulante relacionada ao exercício físico ainda não foi totalmente elucidada (LUKASKI, 1996). Porém, existem várias razões possíveis para baixas concentrações do zinco plasmático em atletas, incluindo a baixa ingestão pela dieta, a perda excessiva durante os exercícios, expansão do volume plasmático durante o treino, que dilui a concentração de zinco, e a redistribuição do zinco plasmático para outros tecidos (CARVALHO, 2003a). 
Agapito, N. et al./Revista Eletrônica de Farmácia Vol 5(3), 09 - 22, 2008.

O zinco tem um papel fundamental no metabolismo orgânico, porém, verifica-se que ainda há ainda muitas questões a serem respondidas sobre funções, homeostasia, danos causados pela deficiência, bem como, suplementação do zinco em várias situações. Assim, sugere-se que muitas pesquisas devem ser realizadas com este mineral, no sentido de mostrar cada vez mais a importância deste para a nutrição humana (MAFRA \& COZZOLINO, 2004). A ingestão recomendada de zinco na dieta é de $8 \mathrm{mg} /$ dia para mulheres e de $11 \mathrm{mg} / \mathrm{dia}$ para homens. Cabe ressaltar que esse consumo suplementar deve ser feito com cautela para evitar possíveis efeitos adversos. A suplementação excessiva de zinco (50 mg/dia) pode inibir a absorção de cobre proveniente da dieta. Além disso, a suplementação de $160 \mathrm{mg}$ de zinco por dia, durante 16 semanas, foi associada à redução da concentração de lipoproteína plasmática de alta densidade (HDL) em homens (KOURY \& MARINO, 2003).

\section{2) Ferro}

Como constituinte da hemoglobina, o ferro é necessário para o transporte de oxigênio e dióxido de carbono no processo da respiração. O ferro é também componente de várias enzimas, como as citocromos oxidases, que são críticas para a produção de energia e de várias enzimas necessárias para o sistema imune (CARVALHO, 2003a). Além do fator hematopoiético, o ferro é essencial para a proliferação celular e metabolismo oxidativo de vários tecidos, e sua depleção comprometem diversas funções essenciais (BHASKARAM, 2002).

O estado nutricional relativo ao ferro em atletas é especialmente importante devido ao papel central deste mineral no transporte de oxigênio, síntese de hemoglobina, mioglobina, e algumas enzimas fundamentais para a produção de energia. Com relação às reservas de ferro, vários estudos indicam uma diminuição destas após temporadas de treinos e competições. Em especial as atletas femininas estão expostas a um risco maior de desenvolverem deficiência de ferro. As mulheres podem ter uma prevalência aumentada de alterações de ferro no corpo, relacionadas ao exercício, devido ao balanço negativo de ferro (CARVALHO, 2003a).

$\mathrm{O} \mathrm{VO}_{2}$ máx é importante, pois expressa a capacidade máxima de transporte e de utilização de oxigênio durante o exercício. A captação de oxigênio aumenta como uma função linear da taxa de trabalho até que o $\mathrm{VO}_{2}$ máx seja atingido. Portanto o $\mathrm{VO}_{2}$ máx representa um "teto fisiológico" da capacidade do sistema de transporte de oxigênio de liberar $\mathrm{O}_{2}$ para os músculos que estão contraindo. Conseqüentemente uma redução do $\mathrm{VO}_{2}$ máx acarreta menor oxigênio disponível aos músculos, afetando, portanto o desempenho do atleta. Estudos ilustraram que $0 \mathrm{VO}_{2}$ máx, por estar relacionado com a capacidade carreadora de oxigênio, está correlacionado com o grau de anemia (CARVALHO, 2003a).

O baixo nível de ferro, que ocorre em cerca de $15 \%$ da população mundial, causa fadiga e anemia, afetando a performance e o sistema imunológico. Recomenda-se atenção especial ao consumo de alimentos com ferro de elevada biodisponibilidade. Em relação ao ferro, recomenda-se $15 \mathrm{mg} / \mathrm{dia}$ para a população feminina e 10 $\mathrm{mg} / \mathrm{dia}$ para a masculina. Tais necessidades são contempladas pela manipulação dietética, não sendo necessária a suplementação. O ferro possui recomendação de grau A e nível de evidência 2 (CARVALHO, 2003).

\section{CONCLUSÃO}

- O trabalho apresentou procedimentos de caráter educacional, tratando a necessidade de orientação farmacêutica no uso de medicamentos e suplementos nutricionais a praticantes de atividade física de endurance.

- A interação entre a equipe pesquisadora e o esportista, permitiu conscientização deste quanto a importância de buscar informações a respeito de substâncias que o mesmo venha a consumir.

- Destaca-se o desequilíbrio hidroeletrolítico como um dos principais pontos críticos durante a prática de atividades físicas de endurance. Os profissionais da área da saúde devem orientar quanto à reposição adequada de água e sais minerais.

- O excesso de treinamento realizado por esportistas e atletas pode levar a um desequilíbrio fisiológico, onde a demanda de micronutrientes e oxigênio não são supridos. Deste modo, há uma necessidade de suplementação alimentar adequada. Porém, grande parte dos suplementos disponíveis não possui eficácia e segurança de uso comprovada por evidências cientificas.

- O farmacêutico deve apoiar a regulamentação, o controle de qualidade para produção, buscando segurança e eficácia, e a fiscalização da comercialização de produtos de suplementação nutricional. Pode, ainda, contribuir para a pesquisa na área da Medicina Esportiva e orientar os atletas e esportistas quanto aos efeitos farmacológicos, toxicológicos e adversos, interações, posologia dos suplementos e medicamentos.

\section{REFERÊNCIAS}

BRASIL, Portaria $\mathrm{n} \cong$ 32, de 13 de janeiro de 1998. Aprova o Regulamento Técnico para Suplementos Vitamínicos e ou de Minerais, constante do anexo desta Portaria. Ministério da Saúde. Secretaria de Vigilância Sanitária. Diário Oficial da União; Poder Executivo, de 15 de janeiro de 1998. 
Agapito, N. et al./Revista Eletrônica de Farmácia Vol 5(3), 09 - 22, 2008.

BRASIL, Portaria $\mathrm{n} \cong$ 40, de 13 de janeiro de 1998. Regulamento que estabelece normas para Níveis de Dosagens Diárias de Vitaminas e Minerais em Medicamentos. Ministério da Saúde. Secretaria de Vigilância Sanitária. Diário Oficial da União; Poder Executivo, de 15 de janeiro de 1998.

BRASIL, Resolução № 417 de 29 de setembro de 2004. Código de ética da profissão farmacêutica. Conselho Federal de Farmácia. Diário Oficial da União; Poder Executivo, 17 de novembro de 2004.

BARR, S. I.; COSTILL, D. L.; FINK, W. Fluid replacement during prolonged exercise: effects of water, saline, or no fluid. Medicine Science Sports Exercise. v. 23, p. 811-17, 1991.

BASSIT, R., A.; MALVERDI, M. A. Avaliação nutricional de triatletas. Revista Paulista de Educação Física. São Paulo, v. 12, n. 1, p. 42-53, 1998.

BHASKARAM, P. Micronutrient malnutrition, infection, and imunity: an overview. Nutrition Reviews. v. 60, n. 5, p. 40-45, 2002. Suplemento.

BIANCHI, M. L. P.; ANTUNES, L. M. G. Radicais livres e os principais antioxidantes da dieta. Revista de Nutrição. v.12, n.2, p.123-130, 1999.

BRESSAN, F. O método do estudo de caso. Administração On Line FECAP, 2000 [online]. Disponível: http://www.fecap.br/adm online/art11/flavio.htm [capturado em 30 de junho de 2008].

BROUNS, F. Functional foods for athletes. Trends in Food Science and Technology. v. 8, p. 358-363, 1997.

CARVALHO, L. F. S. B. Estado nutricional relativo a ferro e zinco de atletas profissionais de uma equipe feminina brasileira de voleibol. Dissertação de Mestrado em Nutrição (Metabolismo e Dietética) da Universidade Federal de Santa Catarina. Florianópolis, 2003a. 93 p.

CARVALHO, T. Modificações dietéticas, reposição hídrica, suplementos alimentares e drogas: comprovação de ação ergogênica e potenciais riscos para a saúde. Revista Brasileira de Medicina do Esporte. v. 9 n. 2, p. 1-13, 2003.

CLAUMANN, R. C. N. O farmacêutico e a atenção farmacêutica no novo contexto da saúde. Dissertação de mestrado em Engenharia de Produção, Universidade Federal de Santa Catarina, 2003. 96 p.

FERREIRA, A, M, D; RIBEIRO, B, G; SOARES, E, A. Consumo de carboidratos e lipídios no desempenho em exercícios de ultraresistência. Revista Brasileira de Medicina Esportiva. v.7, n. 2, p. 67-74, 2001.

FONTANA, K. E.; VALDES, H.; BALDISSERA, V. Glutamina como suplemento ergogênico. Revista Brasileira de Ciência e Movimento. v. 11, n. 3, p. 91-96, 2003.

FROILAND, K.; KOSZEWSKI, W.; HINGST, J.; KOPECKY, L Nutritional supplement use among college athletes and their sources of information. International Journal Sports Nutricion Exercise Metabolism. v.14, n.1, p. 104-20, 2004.

HOSEY, R. G.; GLAZER, J. L. The ergogenics of fluid and electrolyte balance. Current Sports Medicine Reports. v. 3, p.219-23, 2004.

HUFFMAN, S. L.; BAKER, J.; SHUMANN, M. A.; ZEHNER, E. R. La promoción de suplementos de multivitaminas y minerals para mujeres en edad fértil de los países em desarrollo. Proyecto LINKAGES, p. 1-42, 1998.

IVAMA, A. M.; NOBLAT, L.; CASTRO, M. S.; OLIVEIRA, N. B. N. V.; JARAMILLO, N. M.; RECH, N. Consenso brasileiro de atenção farmacêutica: proposta. Brasília: Organização Pan-Americana da Saúde, 2002. 24 p.

KANTER, M. Free radicals, exercise and antioxidant supplementation. Proceedings of the Nutrition Society. v. 57, n.1, p. 9-13, 1998.

KOURY, J. C.; MARINO, C. Zinco, estresse oxidativo e atividade física. Revista de Nutrição. v.16, n.4, p.433-441, 2003.

LIRA, C. A. B.; VANCINI, R. L. Sintomas gastrointestinais em atletas de endurance. Centro de Estudos de Fisiologia do Exercício, Universidade federal de São Paulo, 2005. 
Agapito, N. et al./Revista Eletrônica de Farmácia Vol 5(3), 09 - 22, 2008.

LUKASKI, H. C.; SIDERS, W. A.; HOVERSON, B. S.; GALLAGHER, S. K. Iron, copper, magnesium and zinc status as predictors of swimming performance. International Journal of Sports Medicine. v. 17, n. 7, p. 535-540, 1996.

MAFRA, D.; COZZOLINO, S. M. F. The importance of zinc in human nutrition. Revista de Nutrição. v.17, n.1, p.7987, 2004.

MARINS, J. C. B.; DANTAS, E. H. M.; NAVARO, S. Z. Diferentes tipos de hidratação durante o exercício prolongado e sua influência sobre o sódio plasmático. Revista Brasileira de Ciência e Movimento. v. 11, p.13-22, 2003.

MARON, B. J.; MITCHELL, J. H. Revised eligibility recommendations for competitive athletes with cardiovascular abnormalities. Journal of American College of Cardioliology. v. 24, n. 24, p. 848-850, 1994.

MARZZOCO, A.; TORRES, B. B. Bioquímica Básica. 2 ed. Rio de Janeiro: Guanabara Koogan, 1999. p. 252-253.

MELLO, E. D.; MENDES, F. V. L. Fármacos utilizados em nutrição e anemia. 2008 [on line]. Disponível: http://www.anvisa.gov.br/divulga/public/livro eletronico/nutricao.html\# Toc24800715 [capturado em 25 de abril de 2008].

MURRAY, B.; EICHNER, E. R.; STOFAN, J. Hiponatremia em atletas. Sports Science Exchange 37. V. 16, n 1, p. $1-6,2003$.

NETO, T. L. B. A Controvérsia dos Agentes Ergogênicos: Estamos Subestimando os Efeitos Naturais da Atividade Física? Arquivos Brasileiros de Endocrinologia \& Metabologia. v. 45 n. 2, p.121-122, 2001.

NOAKES, T. D.; SHARWOOD, K.; COLLINS, M.; PERKINS, D. R. The dipsomania of great distance: water intoxication in an Ironman triathlete. Brazil Journal Sports Medicine. v. 38, n. 4, p. e16-e16, 2004.

POWERS, S.K.; HOWLEY, E.T. Fisiologia do exercício. 1 ed. Barueri: Manole, 2000. p. 324-432.

RAIA, J. 2008 [online]. Sodium and Dehydration. Disponível: http://www.ultrunr.com/sodium.html [capturado em 01 jun 2008].

ROSE, E. H.; FEDER, M. G.; BENTO, R. M. A.; NETO, F. R. A. Uso de Medicamentos no Esporte. Confederação Brasileira de Triathlon, 2004 [on line]. Disponível: http://www.cbtri.org.br/docs/Livreto_COB.pdf [capturado em 01 de maio de 2008].

SANTOS, K. M. O.; FILHO, A. A. B. Consumo de produtos vitamínicos entre universitários de São Paulo. Revista de Saúde Pública. v.36, n.2, p. 250-253, 2002.

SCHWENK, T. L.; COSTLEY, C. D. When food becames a drug: nonanabolic nutritional supplement use in athletes. The American Journal of Sports Medicine. Waltham, v. 30, n.6, p. 907-916, 2002.

SILVA, C. R. M; NAVES, M. M. V. Suplementação de vitaminas na prevenção de câncer. Revista de Nutrição. v.14, n.2, p.135-143, 2001.

SOCIEDADE BRASILEIRA DE NUTRIÇÃO, 2008 [on line]. Disponível:

http://www.sbnpe.com.br/boletins/50/1-suplementacao-nutricional-ambiente-hospitalar.htm [capturado em $10 \mathrm{de}$ abril de 2008].

SPEEDY, D. B.; NOAKES, T. D.; ROGERS, I. R.; Hyponatremia in ultradistance triathletes. Medicine Science Sports Exercise. v. 31, p. 809-15, 1999.

TUMA, I. L. Perspectiva de assistência farmacêutica. Pharmácia Brasileira, Brasília, v. 3, n. 18, p. 47, jan./fev. 2000.

TWERENBOLD, R.; KNECHTLE, B.; KAKEBEEKE, T. H.; ESER, P.; MÜLLER, G.; VON ARX, P.; KNECHT, H. Effects of different sodium concentrations in replacement fluids during prolonged exercise in women. Brazil Journal Sports Medicine. v.37, p.300-303, 2003. 
Agapito, N. et al./Revista Eletrônica de Farmácia Vol 5(3), 09 - 22, 2008.

UBELS, F. L. ; VAN ESSEN, G. G. ; JONG, P. E. ; STEGEMAN, C. A. Exercise induced macroscopic hematuria: run for a diagnosis? Nephrology Dialysis Transplantation. v.14, p. 2030-2031, 1999.

MELÉNDEZ, G., V.; MARTINS, I. S.; CERVATO, A. M.; FORNÉS, S.; MARUCCI, M. F. N. Consumo alimentar de vitaminas e minerais em adultos residentes em área metropolitana de São Paulo, Brasil. Revista de Saúde Pública. v. 31, n. 2, p.157-162, 1997. 